\title{
Cuando tocar se convierte en tocar: Mente, cuerpo y sexualidad en un nuevo psicoanálisis relacional ${ }^{1}$
}

\author{
Jonathan H. Slavin², Ph.D., ABPP y Miki Rahmani3, M.A. \\ Natalia Garcia (traductora)
}

Los escritos psicoanalíticos recientes han implicado un esfuerzo por reintegrar el cuerpo y la experiencia corporal en nuestra comprensión de la construcción de la mente. Esta integración es crítica para el psicoanálisis ya que, como está cada vez más claro en la ciencia, el cerebro físico, el órgano que experimenta el cuerpo y la mente son uno. Como ha señalado Kandel (2013), "la psicoterapia es un tratamiento biológico, una terapia cerebral. Produce cambios físicos duraderos y detectables en nuestro cerebro". Sin embargo, ¿podemos volver al cerebro, al cuerpo, a la materialidad, a tratar de encontrar nuestras mentes en el cuerpo sin volver a una integración psicoanalítica fundamental de la centralidad absoluta de la sexualidad en nuestro desarrollo mental? ¿No debe ser un nuevo psicoanálisis relacional el que tenga en cuenta el cuerpo en la mente y que también tenga en cuenta la comprensión convincente de Freud de nuestra experiencia sexual en el núcleo y los límites de nuestros mundos relacionales? En este artículo exploraremos algunas de las formas en que la sexualidad individual, la huella de la persona, incorpora todo el potencial de la experiencia humana en nosotros mismos y en la relación: lo pulsional y la rendición; los límites de la pasión y la violación; la paradoja de la relación y la disociación; la sintonía y el deseo personal. Nuestro enfoque será sobre la sexualidad en las poderosas interacciones que cambian el cerebro, entre pacientes y terapeutas, en el proceso de tratamiento.

Palabras clave: huella sexual, sexualidad, cuerpo, contratransferencia, metáfora, mente, neutralidad experiencial

Recent psychoanalytic writing has involved an effort to reintegrate the body and bodily experiencing into our understanding of the construction of the mind. This integration is critical for psychoanalysis since, as is increasingly clear in science, the physical brain, the body's experiencing organ, and mind, are one. As Kandel (2013) has noted, "psychotherapy is a biological treatment, a brain therapy. It produces lasting, detectable physical changes in our brain". Yet can we return to the brain, to the body, to materiality, to trying to find our minds in the body without returning to a fundamental psychoanalytic integration of the absolute centrality of sexuality in our mental development? Mustn't a new relational psychoanalysis that reckons with the body in the mind also reckon with Freud's compelling understanding of our sexual experiencing at the core and edge of our relational worlds?. In this paper we will explore some of the ways one's individual sexuality, one's sexual fingerprint, embodies all of the potential for human experiencing in ourselves and in relationship: the driven and surrendering; the edges of passion and violation; the paradox of relationship and dissociation; attunement and personal desire. Our focus will be on sexuality in the powerful, brain changing interactions between patients and therapists in the treatment process.

Key Words: sexual fingerprint, sexuality, body, countertransference, metaphor, mind, experiential neutrality. English Title: Slow Dancing: Mind, Body, and Sexuality in a New Relational Psychoanalysis

\section{Cita bibliográfica / Reference citation:}

Slavin, J.H. y Rahmani, M. (2019). Cuando tocar se convierte en tocar: Mente, cuerpo y sexualidad en un nuevo psicoanálisis relacional. Clínica e Investigación Relacional, 13 (2): 301-315. [ISSN 19882939] [Recuperado de www.ceir.info ] DOI: 10.21110/19882939.2019.130201 
Leonard Cohen canta4:

Suzanne te lleva a su refugio a orillas del rio

Puedes escuchar lo barcos que pasan

Puedes pasar la noche a su lado

Si, sabes que ella está medio loca

Pero por eso quieres estar allí

$Y$ te ofrece té y naranjas

Que vienen desde la lejana China

Y justo cuando estás por decirle

Que no tienes amor para ofrecerle

Ella se sintoniza contigo

Y deja que el río te responda

Que siempre has sido su amante

Y tú quieres viajar junto a ella

Quieres que viajen juntos a ciegas

Y sabes que ella confiará en $t i$

Porque le has tocado el cuerpo

Su cuerpo perfecto con tu mente.

\section{El psicoanálisis y el cuerpo}

Dentro de la perspectiva relacional, el pensamiento psicoanalítico reciente (Fast, 2006, 2012; Fonagy y Target, 2007; Gentile, 2007, 2008, 2010, 2013) ha intentado reintegrar el cuerpo y la experiencia corporal a nuestro conocimiento sobre la formación de la mente. Este retorno al cuerpo es interesante porque es justamente allí que el psicoanálisis se focalizó en la primera mitad del siglo $\mathrm{XX}$, después de que Freud abandonara la teoría del trauma. Su foco, y el del psicoanálisis clásico, eran la libido, la sexualidad y la experiencia corporal en el desarrollo de la personalidad.

Sin embargo, a esto le siguió una revolución en el psicoanálisis. A partir de Winnicott, de Sullivan en Estados Unidos, y luego con la Psicología del Self y la perspectiva relacional, el psicoanálisis comenzó a moverse en otra dirección, alejándose de la experiencia corporal y acercándose hacia el modo en el cual las relaciones plasman la mente. Esa revolución relacional fue esencial. Le devolvió importancia, en el psicoanálisis, al impacto que la realidad tiene en la formación de la mente, representada por personas reales, interacciones reales y fracasos reales en el desarrollo. 
Es importante tener en cuenta que estas perspectivas "relacionales" no atañen simplemente a interacciones en el mundo real. Más bien, atañen el modo en el que las relaciones, así como son experimentadas por el individuo, configuran el mundo interno, la mente. Los objetos internos no se crean simplemente a partir de fantasías libidinosas engendradas internamente. Están basados en las interacciones reales con personas reales. Además, estas perspectivas relacionales han cambiado el modo de ver el proceso psicoterapéutico. El terapeuta o el analista ya no era el observador externo y objetivo que proporcionaba una especie de insight que de alguna manera producía un cambio. El verdadero agente de cambio son las interacciones reales entre dos personas reales. Durante la evolución del pensamiento psicoanalítico, esta amplia perspectiva relacional nos ha permitido recuperar nuevamente algo que habíamos perdido de vista durante 75 años, o bien el profundo impacto que el trauma real y el abuso sexual tienen sobre muchas, muchísimas personas. Y es precisamente este el punto a partir del cual se desarrolló el psicoanálisis.

Pero ahora es absolutamente necesario que el psicoanálisis efectúe una nueva integración del cuerpo y de la experiencia relacional. Cada vez más investigaciones científicas están evidenciando que el cerebro, el órgano del cuerpo que percibe el mundo, y la mente, la psique, son una unidad. La escisión mente-cuerpo (Fast, 1992), que tiene sus raíces en los ideas de Platón y ha sido reforzada en el pensamiento occidental por el rechazo del cuerpo y la sensualidad de parte de la teología cristiana, ya no se sostiene. Después de casi dos decenios de descubrimientos importantes en estudios del cerebro, Kandel (2013), premio Nobel en Medicina, recientemente afirmó: "La psicoterapia es un tratamiento biológico, una terapia del cerebro. Produce modificaciones físicas detectables y de larga duración en nuestro cerebro". Y efectivamente así es. Todos los estudios efectuados a través de TAC cerebrales muestran que virtualmente todo tipo de psicoterapia, sea de tipo Cognitivo, Conductual, sea de tipo "relacional", produce cambios reales y permanentes en los esquemas de la comunicación cerebral. Eso no está en discusión. Lo que en aún está en discusión, y que debe ser objeto de ulteriores estudios, es si son los aspectos relacionales de un proceso terapéutico o los contenidos de la terapia los que están en el origen del cambio fundamental.

En psicoanálisis retornar al cuerpo, al cerebro, quiere decir encontrar la realidad material y física, el límite entre el cuerpo y la mente en el mundo externo real. Es claro, hace tiempo, que nosotros no podemos continuar pensando solamente en la realidad interna, psíquica. Es cierto que implícitamente sabemos que nuestras mentes funcionan a través de la experiencia de nuestros cuerpos en el mundo físico. No nos referimos sólo a nuestras percepciones, sino también al modo fundamental en el que pensamos. Nosotros pensamos con nuestros cuerpos (Renik, 1993) y a través del encuentro de nuestro cuerpo con el mundo físico. 
Las metáforas son tal vez el mejor ejemplo de esto. Con metáfora se suele indicar un proceso intelectual y mental de abstracción, el uso de una palabra o de una frase para designar o explicar otra. Pero, de hecho, si pensamos en las metáforas, estas no son sólo la sustitución de algunas palabras con otras. Casi siempre nosotros utilizamos el mundo físico y el encuentro con nuestro cuerpo y su relación con él 5 de modo de comprender mejor aún los conceptos más abstractos y nuestros sentimientos humanos más complejos. Pongamos algunos ejemplos: en esta discusión, si nos hacen algunas preguntas difíciles, en inglés diríamos que nos tienen en puntas de pie (en castellano: que nos tienen sobre ascuas), o que debemos pensar en dos pies; el hecho de que alguien (en el auditorio) esté durmiendo mientras hablamos nos destroza; esperamos que alguien haga alguna pregunta profunda; intentamos no permanecer sobre la superficie de las cosas; y ayer, cuando recibimos la noticia de nuestro pequeño stock de Apple tocamos el cielo con las manos.

Es evidente que usamos nuestro cuerpo en función de nuestra mente. Pero, ¿es posible intentar encontrar nuestra mente en el cuerpo - incluso en su expresión más abstracta, la metáfora, sin regresar a la básica integración psicoanalítica de la absoluta centralidad de la sexualidad en nuestro desarrollo mental? ¿No son la sexualidad, la sensualidad, el placer físico, los modos primarios en que nuestro cuerpo experimenta el mundo desde el nacimiento? Y, si así fuere, un nuevo psicoanálisis relacional que se ocupe del cuerpo en la mente, ¿no debería ocuparse también de la eficaz explicación de Freud sobre el rol fundamental de nuestra experiencia sexual al centro y al límite de nuestros mundos relacionales?

Veamos lo que Freud (1912), el primer analista relacional, dice respecto al origen de las relaciones:

...se nos impone esta intelección: todos nuestros vínculos de sentimiento, simpatía, amistad, confianza y similares, que valorizamos en la vida, se enlazan genéticamente con la sexualidad y se han desarrollado por debilitamiento de la meta sexual a partir de unos apetitos puramente sexuales, por más puros y no sensuales que se presenten ellos ante nuestra autopercepción consciente. En el origen solo tuvimos noticias de objetos sexuales; y el psicoanálisis nos muestra que las personas de nuestra realidad objetiva meramente estimadas o admiradas pueden seguir siendo objetos sexuales para nuestro inconsciente (p.103).

Retomando el argumento de Freud, en esta discusión esperamos explorar algunos de los modos en los que la sexualidad está a la base de la elaboración de todas nuestras experiencias relacionales, de la formación de nuestras mentes y relaciones en la potente 
interacción entre padres e hijos, de las relaciones sexuales entre adultos, y las implicaciones para lo que sucede entre pacientes y terapeutas.

Queremos subrayar que sabemos que lo que estamos diciendo no es del todo nuevo. En parte algunas cosas ya fueron dichas en pasado. Lo que esperamos hacer es proporcionar es algo así como una nueva "lente" para observar conceptos que ya son familiares. Comencemos con dos viñetas clínicas.

\section{Perder la mente en el sexo}

Kurt, mi paciente, no lograba encontrar su mente. Un hombre de alrededor de treinta años, Kurt estaba perdido en un pantano interior de incertidumbre y ambigüedad, y pensaba que su vida era enormemente dificultosa. Pasaba de una relación a otra, relaciones que podían tener una duración variable. Al principio se sentía extremadamente involucrado por las mujeres que encontraba, pero gradualmente le incumbía una sensación de ansiosa desorientación. ¿Por qué estaba con ella? No lograba encontrar sus sentimientos. Yo también me sentía perdido.

Gradualmente, con el pasar del tiempo, afloró la pintura ${ }^{6}$ del mundo en el que Kurt había crecido. Tenía padres que querían su bien, que le habían dado todo lo mejor que podían materialmente. Comida, casa, una buena educación. Pero ambos estaban oprimidos por dos traumas importantes, aunque diferentes, que remontaban al periodo del desarrollo. El padre, que había vivido la guerra cuando era niño, consumido por su trauma, estaba emocionalmente inaccesible. Su madre, cuya madre había sido muy brutal con ella, intentaba calmar y consolar a Kurt, primero de niño y ahora de adulto, con comentarios superficiales que no tenían nunca en consideración su real soledad emotiva y su dolor. Fuera porque eran incapaces de reconocer la necesidad de Kurt de tener un contacto real con ellos, de tocar sus mentes con la de él, o que sus esfuerzos hayan removido la vulnerabilidad traumatizada de cada uno de ellos, cada padre era, a su manera, verdaderamente inaccesible. Sus intentos de encontrar reconocimiento, en la cercanía, en la necesidad de ser simplemente visto, no lo habían llevado a ningún lado.

Después de muchos meses de tratamiento, se ha trabajado mucho sobre las experiencias de Kurt durante su desarrollo. $Y$ además conoció a una mujer y entraron enseguida en sintonía. La intensidad crece rápidamente entre ellos. Ambos sienten curiosidad por los intereses del otro; él la encuentra extremadamente atractiva. Parecen realmente haber encontrado un contacto. 
Tocar se convierte en tocar. La excitación del reconocimiento, la experiencia de dos personas que se encuentran, el encuentro de sus mentes - fundamentalmente sexuales y corporales en el origen, como sugerido por Freud (1912), lo que Jessica Benjamin define como el placer del reconocimiento - pronto se convierte en sexo.

Algunas sesiones más tarde, Kurt tiene una expresión muy triste. Está realmente muy decaído. "No lo sé, Jonathan", me dice, "entramos en intimidad. Fue una experiencia increíble. O mejor, debería ser increíble. Estoy seguro de que otros hombres lo pensarían así. Pero pasa algo", Kurt dice, "ella se pierde tanto en sí misma, en sus orgasmos, y permanece allí durante tan largo tiempo que me siento vacío y desconectado". Así como lo describe Kurt, parece claro que él no se siente parte de un proceso entre ellos, entre las pasiones y los cuerpos de ambos. Ella está en su espacio y él, una vez más, se siente perdido.

\section{Encontrar la mente en el sexo}

Una terapeuta novel está trabajando con un hombre con una autoestima muy frágil, percibida de manera dolorosa sobre todo en sus relaciones con las mujeres. La terapeuta quiere ayudar, pero ella misma es escéptica acerca de la terapia. ¿Por qué no brindar solo un apoyo? Lentamente, gracias a la atenta guía de su supervisora, la terapeuta comienza a escuchar y el paciente le cuenta más acerca de sí y de su experiencia. Pero tras una sesión reciente, la terapeuta le dice a su supervisora que está completamente confundida. No logra juntar las piezas. El paciente estaba en una fiesta y estaba bailando una pieza lenta con una amiga. Entre ellos comienza a suceder algo, algo profundo, no solo sexual, dice él, sino algo vital y excitante. Él percibe que ella siente la misma cosa. Aún más sorprendentemente, ella le pregunta: "¿Tú también sentiste algo realmente especial?" Increíblemente ella también tenía la urgencia de saber si la cosa era recíproca.

La terapeuta no recordaba mucho más de la sesión, excepto el final. El paciente había dicho que de lo que más se quería deshacer era del pequeño niño necesitado dentro de él, que odia. De golpe, la terapeuta se oyó mientras decía: "¿Por qué no puede simplemente amarlo?". El paciente se quedó conmovido. Dijo: "No lo había pensado nunca". La terapeuta no entiende de donde ha llegado ese comentario suyo, pero recuerda que había imaginado cuan hermoso debería haber sido de niño el paciente, mientras pensaba en su propio hijo pequeño.

Mientras la supervisora y la terapeuta hablaban, volvieron al tema de la pieza lenta. La terapeuta contó como lo había imaginado y sentido dentro de ella, en su cuerpo. La supervisora reconoció que ella también había sentido algo. El contenido de la sesión volvió a 
su mente. La terapeuta recordó que el paciente le había hablado del humillante rechazo que había experimentado en cuarto grado por parte de una niña a quién le había pedido ser su novia. Toda la vida se había sentido no visto. Odiaba eso y se odiaba a sí mismo. La terapeuta recordó que el paciente le había dicho que quería que sobre su tumba [su epitafio] escribieran "aquí yace una persona real". Ahora, después de la pieza lenta y de la reacción de la muchacha, piensa que debería ser "aquí yace una persona real con conexiones reales". Había sentido que nadie, especialmente las mujeres, podían verlo realmente.

Supervisora y terapeuta hablaron luego sobre la manera en la que las imágenes del baile lento habían revitalizado a ambas, y como habían permitido que la terapeuta entrara en contacto con el paciente, lo sintiera como hombre y como muchacho, de modo que él pudiera comenzar a entrar en contacto con el pequeño niño dentro de él.

\section{Discusión}

Detengámonos un momento a considerar el significado de estas dos viñetas. En el caso de la pieza lenta, la terapeuta está sorprendida por el poder del proceso. Mientras escuchamos esta viñeta sobre el baile lento, un baile íntimo, tal vez también nosotros tuvimos nuestras propias imágenes y sensaciones; nosotros también podemos sentir el sobreponerse de experiencias de respuestas humanas profundamente psíquicas y corporales $y$, con ellas, una correspondiente capacidad de comprensión más profunda. Cuando entramos en la mente de otra persona y somos tocados por la suya, comprendemos estas experiencias a través y con nuestros cuerpos.

El caso de Kurt nos dice mucho sobre el increíble esfuerzo que algunas personas pueden hacer para encontrar su propia mente en el mundo material, incluso el mundo del cuerpo y el contacto mente/cuerpo con la realidad. Kurt perdió la cabeza con su novia, o mejor, se sintió perdido dentro de ella, porque, así como en la experiencia con sus padres, sintió que nadie estaba ahí, en cada acepción corporal y emotiva que esta frase pueda tener. Esta es una terrible y horrible perdida de anclaje en el propio cuerpo y en el mundo, muy diferente de lo que puede querer decir "perder la cabeza" en un momento de pasión.

En los ejemplos de Kurt y de la pieza lenta vemos dos polos que están siempre potencialmente presentes en cada uno de nosotros, entre disociación y relaciones, entre tener nuestra mente con nosotros mientras trazamos aquella de otra persona, o cancelar el contacto, perder nuestra mente y la del otro. Benjamin (1995) se refiere a la "tensión constante entre el reconocer al otro y afirmar el sí-mismo" (p.69, cursivo en el original). Cuando la oscilación entre estos dos polos está ausente, cuando falla la tensión 
intersubjetiva, no hay algún baile lento, la mente del paciente esta disociada entre la omnipotencia y la abyecta rendición (Benjamin, 1995) y se experimenta el esencial vacío de la existencia, así como lo experimentó profundamente Kurt.

Lo que esperamos sugerir en esta discusión es que la sexualidad encarna todo este potencial de experiencias humanas en nosotros y en las relaciones: el impulso y la rendición, desde la superficie de la mente, y aquella del cuerpo, hasta el límite del casi demasiado, ya sea moviendo pasión o, con alguna diferencia, provocando violación. En la sexualidad, en un único y solo momento, se ilumina la paradoja de la mente humana y de las relaciones entre los hombres: la capacidad de tener el otro en la mente, de tenerlos como custodios de nuestra experiencia de agency mientras nos responden; $y$, al mismo tiempo, de cancelarlos cuando privilegian los deseos de nuestra mente sentidos tan perentoriamente en nuestros cuerpos. ${ }^{7}$

Es fundamental para el pensamiento psicoanalítico comprender que estos modos de sentir son creados y modelados a partir de las primeras interacciones entre madre y niño, en el contacto corporal que está a la base de todas las sucesivas interacciones y del modo en el que serán sentidas, sentidas como experiencias corporales, sexuales y emotivas. Además, cada padre le brinda a cada hijo lo que nosotros quisiéramos llamar las huellas de la sexualidad a su experiencia con los hijos; nos referimos al inimitable y único modelo de su experiencia de la sexualidad, así como fue elaborada en su vida, como serán en la relación con sus hijos y como los percibirán; su capacidad de placer, excitación, sintonización, contención, disociación, muerte, ausencia es distinta e única en cada persona, como una huella. Lo que excita a un padre de un hijo asusta a otro. $Y$ nuestras mentes y nuestro modo de experimentar, incluso el modo en el que experimentamos la sexualidad, son modelados por estos procesos, por las huellas sexuales de nuestros primeros caretaker (Slavin 2011). Ruth Stein (1998) habló de como la madre "establece" su propia sexualidad en el hijo y crea las bases para su viaje erótico a través de su potencial erótico y seductivo. Con otro lenguaje, Freud dijo casi la misma cosa. ${ }^{8}$

\section{El baile lento y las huellas sexuales en el tratamiento}

¿Qué sucede con las huellas sexuales del terapeuta? ¿Y con las del paciente? Claramente, el tema principal de este argumento es que el encuentro entre la mente del paciente y la del terapeuta incluye los cuerpos y la sexualidad de ambos. No nos referimos solo a los sentimientos sexuales de atracción habitual y conscientemente experimentados que inevitablemente están presentes en algunas relaciones terapéuticas. Tampoco a lo que llamamos "contratransferencia". Pero si el cuerpo y la sexualidad son fundamentales para la 
manera en la que conocemos y negociamos el mundo, entonces también nuestros cuerpos y nuestra sexualidad son fundamentales para la creación y evolución de la relación terapéutica.

Mientras estudiamos el rol de la experiencia sexual corporal y física en la "arena" del tratamiento, nos encontramos frente a la difícil tarea que los terapeutas deben emprender. La naturaleza frágil y delicada de la sexualidad dentro de un tratamiento, así como en otros contextos, es clara. Punto fundamental de la sexualidad, en todo contexto, es que se coloca en el límite entre sintonización y violación. Pero justamente este límite está a la base del poder y de la pasión del acto sexual. Piensen en el momento antes del primer beso. ¿Sucederá?, ¿será demasiado pronto?, ¿quién hará el primer paso?, ¿debería hacerlo yo?, ¿cómo responderá él o ella? Alguien tiene que "romper el hielo". E incluso en el baile, alguien debe conducir. Veamos qué papel podría tener todo esto en el ámbito psicoterapéutico.

Recientemente tuvimos oportunidad de discutir dos artículos (Steve Kuchuch, editor de la revista Psychoanalytic Perspectives, y Galit Atlas, una analista de Nueva York), sobre como experimentaron la sexualidad en el tratamiento de dos pacientes suyos. Esperamos poder transmitir de manera suficiente lo que pasó en sus trabajos para hacer que estos ejemplos sean útiles.

Steve y Galit son dos personas diferentes, con diferente orientación sexual, pero estuvieron disponibles para discutir la inimitable configuración, las huellas, de su sexualidad con sus pacientes.

Steve, un hombre predominantemente homosexual, se encontró involucrado, excitado en el cuerpo y en la fantasía, por su paciente, un hombre extremadamente atractivo, y en apariencia prevalentemente heterosexual. Resonando con su personal experiencia de niño con un padre terrorífico, él ve, él siente, el niño pequeño solo que llora, que está dentro de su paciente. Lo ama. Quiere abrazarlo, sostenerlo, besarlo, hacer el amor con él. Y la teoría sobre la acción terapéutica de Steve apoya sobre esto. Esta resonancia con la experiencia de su paciente, el saber lo que se siente desde adentro, los temores y los deseos — incluso el modo en el que le permitían momentos de insight interpretativo y el modo en el que venía procesado entre ellos, pero no más allá, sin rebasar el punto de violación - permitieron la reconfiguración de las huellas sexuales del paciente, permitiéndole de entrar en un nuevo modo de relacionarse íntimamente. Sus relaciones habían estado congeladas durante toda su vida: logró formar una pareja, casarse y ser padre.

Las cosas fueron distintas en el caso de Galit. Su paciente, una mujer, vino a la primera sesión, se sentó, abrió las piernas, puso su gran cartera entre ellas y vació todo su contenido en el suelo. Desde el principio, cuando abre la cartera entre las piernas, la paciente transpira una sexualidad caótica, grosera, provocante y también un poco agresiva. Galit no se sentía 
atraída, en el modo en el cual se sentía atraído Steve, por la experiencia interior de su paciente o de su trauma. Su huella sexual es diferente. Galit quedó muy turbada por lo que surgió, o mejor dicho explotó, durante el tratamiento. Pero no del todo. Algo le permitió mantener un contacto firme con sí misma y se mostró muy capaz de manejar la situación. En un momento, de manera bastante inconsciente, discutiendo la experiencia de la paciente, Galit usa sus mismas palabras sexuales y gráficas. La paciente está consternada. "¿Realmente utilicé esas palabras?". Y ahí sucede algo transformativo. Escuchando las palabras chocantes de Galit, la paciente siente algo en su mente, tal vez lo siente y lo ve en el cuerpo, de una manera distinta. Se debe confrontar con su propia experiencia de violación y sexualidad violada.

En estas dos instancias vemos como a veces la resonancia de las huellas sexuales de ambas partes permite un gran cambio terapéutico. En otros casos la experiencia puede ser de destrucción, desregulación, intrusión. De todos modos, vemos como a través de un proceso que Galit llevó a cabo dentro de sí, la sexualidad fundamental de la paciente también se transforma. La mente de la paciente cambió y, a través de este trabajo intensivo, también la experiencia del cuerpo cambió.

Ni Steve ni Galit decidieron responder de la manera en la que lo hicieron. Así como cada uno de nosotros tuvo sus propias imágenes y sus propias experiencias corporales cuando hablamos del primer beso, del baile lento, así fue para el sentir sexual que surgió en las mentes y en los cuerpos de Steve y Galit cuando se sentaron con sus pacientes. Tal vez alguno de nosotros sintió algo similar con algún paciente. $Y$ es ahí cuando algo decisivo cambia.

Intentemos comprenderlo hasta el fondo. Quita la respiración. Utilizando nuestras huellas personales respecto al sentir sexual, como Steve y Galit, estamos ayudando los pacientes a rescribir las de ellos. Como los pacientes de Steve y Galit, las huellas sexuales reescritas de nuestros pacientes tendrán necesariamente en ellas algunas impresiones y rastros de las nuestras. No hay manera de esquivar esta cosa, y es una cuestión importante en el pensamiento psicoanalítico. Pasamos mas de 100 años intentando evitarlo. Pero nuestras mentes, nuestras mentes sexuales, tendrán un impacto indeleble sobre nuestros pacientes. Este es de hecho el único modo en el que ellos pueden crecer y cambiar (Slavin, 2010).

"¿Tú también sentiste algo realmente especial?" pregunta la joven mujer, después de haber bailado una pieza lenta con su amigo. Y el paciente comienza a rever la comprensión de quien es. No es más una persona real, sino "una persona real con conexiones reales". ¿Esto es psicoterapia? Absolutamente. En cuanto psicoterapeutas intentamos crear nada más y nada menos que momentos como estos, cambios tan poderosos y permanentes en la mente y en el cerebro. 
El psicoanálisis relacional abandonó hace tiempo el concepto de "neutralidad" en su acepción tradicional. Era seguramente una buena idea si se considera lo que se entendía por neutralidad dentro del marco teórico clásico. Pero tal vez tengamos ejemplos de un distinto tipo de neutralidad en estas dos historias. Sea Galit, sea Steve, están sacudidos por sus experiencias y sentimientos, sentimientos sexuales, que no son absolutamente neutrales en el sentido común de esta palabra. En cambio, los acogen con una especie de asombro y apreciación, y una aceptación de la fundamental humanidad de estos sentimientos. Esto, de hecho, es algo que los terapeutas deben hacer cotidianamente. Es lo que hemos decidido hacer y por lo que nuestros pacientes nos pagan.

Lo que nosotros creemos que ayuda a Steve y Galit, y creemos que es esencial para cada terapeuta que espere estar abierto a la entera gama de sentimientos esenciales para el crecimiento del paciente, es que están intensamente interesados en lo que están sintiendo, en lo que está sucediendo en sus mentes y en sus cuerpos. Cada uno de ellos trata su propia sexualidad y la relativa conversación interior de pensamientos y sentimientos que tiene consigo mismo como fundamentalmente inocente (Slavin, 2011) y fascinante. Esto es fundamental. Y nosotros debemos hacer lo mismo.

¿Pero cómo podemos hacer eso? No creemos que las usuales recomendaciones que proporcionamos para la práctica y la ética psicoanalítica sean muy útiles en este caso. $Y$ tampoco creemos que los terapeutas deban ser figuras heroicas atadas firmemente a la silla que sobreviven a la provocación, seducción y atracción del canto de las sirenas de la sexualidad. Y no tendremos nunca el perfecto análisis personal que nos limpie de nuestros personales deseos sexuales sepultados, así que mejor abandonemos esa idea.

Debemos también renunciar a darle toda responsabilidad al paciente, el decir que es la transferencia del paciente lo que lo ha hecho surgir en nosotros. Hemos creado tantas bellas teorías que nos dicen como esta es una buena cosa y cómo podemos utilizarla de manera terapéutica. Pero queremos ser muy claros en separar lo que estamos diciendo aquí de cualquier idea sobre la identificación proyectiva o sobre la contratransferencia. Estos no son conceptos inútiles, pero si toman el dominio en nuestra mente, interfieren con la capacidad del terapeuta de simplemente estar con la experiencia.

Como escribió el poeta E.E. Cummings:

Porque el sentimiento está primero

Quien preste atención

A la sintaxis de las cosas

Nunca va a completamente besarte 


\section{¿Qué deberíamos hacer?}

Una terapeuta pidió una supervisión respecto a una terapia con una paciente lesbiana excepcionalmente suspicaz y distanciante con quien estaba trabajando. Durante más de dos años, la terapeuta había sentido que no había manera de acercarse realmente a la paciente. Pero al final de una sesión reciente, la paciente había descrito un sueño en el que, por primera vez, aparecía un contenido sexual y una representación de la terapeuta. No había quedado tiempo en la sesión para trabajar sobre el sueño, pero, cuando la paciente se había levantado para irse, hubo un momento de cercanía física, casi de contacto, mientras había pasado cerca de la terapeuta. La terapeuta había sentido la tensión sexual. ¿Cómo manejarla? ¿Que debía pensar de la transferencia sexual y, sobre todo, de su excitación "contratransferencial" experimentada por primera vez con esta paciente tan difícil?

Seguramente esta viñeta puede servir de modelo para momentos similares que encontrados en psicoterapia. A partir del clásico escrito de Freud sobre el amor de transferencia (1915) tenemos 100 años de discusiones clínicas y teóricas sobre el tema. Pero lo que pensamos que se podría perder en el modo en el que tradicionalmente pensamos a estas cuestiones es que estos momentos de encuentro, el sueño y el modo en el que se concluyó la sesión, así como la tensión sexual de la terapeuta, no tienen importancia sólo como potencial para la interpretación, para hacer algo, sino que son una considerable conquista en sí. El potencial del tacto, deseo y amor, en todas sus acepciones, que en gran parte faltaron en la vida de la paciente y que la terapia esta ahora introduciendo por primera vez.

En este sentido, colocar inmediatamente lo que sentimos y lo que viene suscitado en nuestros cuerpos en la categoría de la "identificación proyectiva" o de la "contratransferencia" a menudo representa una fuga defensiva de la experiencia del simple poder de una relación que el terapeuta debe, en primer lugar, sentir. ${ }^{9}$

Este es nuestro punto: el hecho que los terapeutas respondan de forma sexual, cuando están en la intimidad con otra persona, es simplemente humano. Está en la base de nuestra capacidad humana de experimentar la sexualidad de manera inocente (Slavin, 2011). No hay alguien "que hace y a quién se lo hacen" ${ }^{10}$, y no hay que rendir cuentas. Fundamentalmente, hay que apreciar el hecho de que respondemos de manera sexual a nuestros pacientes, algunos que encajan con nuestras estructuras preexistentes y fantasías, y otros que no lo hacen, porque somos humanos. Porque es así. Porque las mentes tocan los cuerpos y los cuerpos tocan las mentes. $Y$ en esto se modifican mutuamente para siempre. 


\section{REFERENCIAS}

Atlas, G. (2015). Touch me, know me: The enigma of erotic longing. Psychoanalytic Psychology, 32, 123-139. También en Atlas. G. (en impresión). Enigmatic Knowing: Sexuality, Intimacy and the Ways We Listen. London \& New York: Routledge.

Benjamin, J. (1995). Recognition and destruction: An outline of intersubjectivity. In: Like Subjects, Love Objects: Essays on Recognition and Sexual Difference. New Haven, CT: Yale University Press, pp. 27-48.

Benjamin, J. (2004). Beyond doer and done to: An intersubjective view of thirdness. Psychoanalytic Quarterly, 73:5-46.

Cummings, E.E. (1991). Complete Poems, 1904-1962. New York: Liveright.

Fast, I. (1992). The embodied mind: Toward a relational perspective. Psychoanalytic Dialogues, 2:389409.

Fast, I. (2006). A body-centered mind. Contemporary Psychoanalysis, 42:273-295.

Fast, I. (2012). The primary processes grows up. Contemporary Psychoanalysis, 48:183-198

Fenichel, O. (1941). Problems of Psychoanalytic Technique. New York: The Psychoanalytic Quarterly.

Fonagy, P. and Target, M. (2007). The rooting of the mind in the body: New links between attachment theory and psychoanalytic thought. Journal of the American Psychoanalytic Association, 55:411456.

Freud, S. (1905). Tres ensayos de teoría sexual. Obras Completas de Sigmund Freud, 7. Buenos Aires: Amorrortu.

Freud, S. (1912). Sobre la dinámica de la transferencia. Obras Completas de Sigmund Freud, 12. Buenos Aires: Amorrortu.

Freud, S. (1915). Puntualizaciones sobre el amor de transferencia. Obras Completas de Sigmund Freud, 12. Buenos Aires: Amorrortu.

Gentile, J. (2007). Wrestling with matter: Origins of intersubjectivity. Psychoanalytic Quarterly, 76:547582.

Gentile, J. (2008). Between private and public: Towards a conception of the transitional subject. Int. J. Psycho-Anal., 89:959-976.

Gentile, J. (2010). Weeds on the ruins: Agency, compromise formation, and the quest for intersubjective truth. Psychoanalytic Dialogues, 20:88-109.

Gentile, J. (2013). From truth or dare to show and tell: Reflections on childhood ritual, play, and the evolution of symbolic life. Psychoanalytic Dialogues, 23:150-169.

Kandel, E. (2013). The new science of mind. The New York Times. September 6, 2013. http://www.nytimes.com/2013/og/08/opinion/sunday/the-new-science-of-mind.html?_r=0

Kuchuck, S. (2012). Please (Don't) want me: The therapeutic action of male sexual desire in the treatment of heterosexual men. Contemporary Psychoanalysis, 48:544-562. 
Medina, M. (2012). Beyond Bewilderment and Dread: The Quest for Creativity within Pathological Reenactments of Trauma. Paper presented at the Spring meeting of the Division of Psychoanalysis (39), Santa Fe, New Mexico, April 2012.

Oxenhandler, N. (2001). The Eros of Parenthood: Explorations in Light and Dark. New York: St. Martin's Press.

Renik, O. (1993). Analytic interaction: Conceptualizing technique in light of the analyst's irreducible subjectivity. Psychoanalytic Quarterly, 62:573-571.

Slavin, J. (2010). Becoming an individual: Technically subversive thoughts on the role of the analyst's influence. Psychoanalytic Dialogues, 20:308-324.

Slavin, J. (2011). The innocence of sexuality. In L. Aron \& A. Harris (Eds.), Relational Psychoanalysis, Vol. 4: Expansion of Theory (pp. 45-67). NY: Routledge. (Originally published in 2002, in Psychoanalytic Quarterly, 72:51-80.).

Slavin, J. (2014). Touching becomes touching: Mind, body, and sexuality in a new relational Psychoanalysis. Reply to discussions. Psychoanalytic Perspectives, 11: 49-57.

Original recibido con fecha: $\quad$ 11/3/2019 Revisado: 30/5/2019 Aceptado: 30/06/2019

NOTAS:

1 Publicado en Psychoanalytic Perspectives, 13:2, 152-167, DOI:10.1080/1551806X.2016.1156430. Traducido y reproducido con autorización de Taylor \& Francis y de los autores. Texto base de la intervención de los autores en Madrid, en el seminario clínico realizado en Ágora Relacional-Instituto de Psicoterapia Relacional, 9 de Marzo de 2019. Versiones anteriores de este documento fueron presentadas como una discusión de trabajos de Galit Atlas y Steve Kuchuck en la conferencia sobre Psicología y el Otro, octubre de 2013, Cambridge, Massachusetts; en una conferencia invitada de la Sociedad Psicoanalítica de Nuevo México y la Universidad de Nuevo México, enero de 2015, Albuquerque, NM; y como documento invitado, octubre de 2015, Universidad de Turín, Turín, Italia. Algunas partes previas de este documento también se publicaron como respuesta a las discusiones en Perspectivas psicoanalíticas (Slavin, 2014). Agradecemos a Irene Fast, Ph.D., Mia Medina, Psy.D., y Owen Renik, M.D., por su cuidadosa lectura y sugerencias sustantivas sobre esta discusión.

2 Jonathan H. Slavin, Ph.D., ABPP, es Profesor Clínico de Psicología, Departamento de Psiquiatría, Harvard Medical School; Profesor Clínico Adjunto, Programa Postdoctoral en Psicoterapia y Psicoanálisis, Universidad de Nueva York; Director Fundador, Tufts University Counseling Center (1970-2006); Ex Presidente de la División de Psicoanálisis (39), Asociación Americana de Psicología; y presidente fundador del Instituto de Psicoanálisis de Massachusetts. Las publicaciones del Dr. Slavin se han centrado en elementos experienciales fundamentales en la relación psicoanalítica, incluidos el amor, la sexualidad, el deseo, la veracidad y la agencia personal, así como su papel en la reparación de la mente. Contacto: Jonathan H. Slavin, Ph.D., ABPP; 1234 Walnut Street Newton Highlands, MA 02461; Email: jhslavin@gmail.com

${ }^{3}$ Miki Rahmani, M.A., es Psicóloga jefe del Centro de Salud Mental del Sur de Jerusalén y Profesora Emérita de la Escuela de Educación de la Universidad Hebrea de Jerusalén, Israel. En más de 35 años de enseñanza y consultoría clínica, ha impartido cursos, seminarios y talleres anuales sobre la relación de supervisión, el proceso de supervisión en el trabajo clínico y en la educación, y sobre el proceso de tratamiento.

4 Suzanne. Letra y música de Leonard Cohen. Copyright @ 1967, 1995 Sony/ATV Music Publishing LLC 
Copyright Renewed. All Rights Administered by Sony/ATV Music Publishing LLC, 424 Church Street, Suite 1200, Nashville, TN37219. International Copyright Secured. All Rights Reserved. Reprinted by Permission of Hal Leonard Corporation

${ }^{5}$ Los trabajos de Irene Fast $(1992,2006)$, sobre la naturaleza fundamentalmente corporal de la mente y del pensamiento en psicoanálisis, y de Owen Renik (1993), sobre los aspectos corporales y de movimiento del cuerpo implícitos en el pensamiento preconsciente, especialmente en la clínica en relación con la conciencia de la contratransferencia, tuvieron mucha relevancia en la elaboración de nuestro pensamiento sobre las metáforas y el cuerpo.

${ }^{6}$ Es casi imposible, durante la redacción de este trabajo, no notar las referencias materiales que utilizamos cuando comunicamos. Localizar: encontrar en el mundo físico; un cuadro: algo que vemos, algo material.

${ }^{7}$ Como descrito por Oxenhandler (2001), "... la violación es un elemento del eros. El amor erótico-en cualquier polo del continuum-implica siempre un elemento transgresivo, un desborde de los márgenes normales. Cuanto menos, la transgresión está presente como posibilidad, como algo de lo que no retraemos, con lo que jugamos y nos balanceamos sobre el limite...El permiso concedido al amor físico en ciertos contextos....sucede contra el trasfondo de la prohibición". (p.205, trad. del traductor)

${ }^{8}$ Como escribió Freud (1905):

"La madre se horrorizaría, probablemente, si se le esclareciese que con todas sus ternuras despierta la pulsión sexual de su hijo y prepara su posterior intensidad. Juzga su proceder como amor 'puro', asexual, y aun evita con cuidado aportar a los genitales del niño más excitaciones de las indispensables para el cuidado del cuerpo. Pero ya sabemos que la pulsión sexual no es despertada sólo por la excitación de la zona genital, lo que llamamos ternura infaliblemente ejercerá su efecto un día también sobre las zonas genitales. Ahora bien: si la madre conociera mejor la gran importancia que las pulsiones tienen para toda la vida anímica, para todos los logros éticos y psíquicos, se ahorraría los autorreproches incluso después de ese esclarecimiento. Cuando enseña al niño a amar, no hace sino cumplir su cometido; es que debe convertirse en un hombre íntegro, dotado de una enérgica necesidad sexual, y consumar en su vida todo aquello hacia lo cual la pulsión empuja los seres humanos" (pp.203-204).

9 Medina (2012) trató un tema similar cuando escribió sobre la experiencia y la elaboración de la contratransferencia.

${ }^{10}$ [En inglés "doer and done to".] Tomando prestada esta frase de Benjamin (2004), la estamos utilizando en un sentido estrictamente experiencial, más que intersubjetivo. 